\title{
Two potential problems with philosophical intuitions: muddled intuitions and biased intuitions.
}

\section{--Jeanine Schroer (University of Minnesota-Duluth) and Robert Schroer (University of Minnesota-Duluth)}

\begin{abstract}
One critique of experimental philosophy is that the intuitions of the philosophically untutored should be accorded little to no weight; instead, only the intuitions of professional philosophers should matter. In response to this critique, "experimentalists" often claim that the intuitions of professional philosophers are biased. In this paper, we explore this question of whose intuitions should be disqualified and why.

Much of the literature on this issue focuses on the question of whether the intuitions of professional philosophers are reliable. In contrast, we instead focus on the idea of "muddled" intuitions - i.e. intuitions that are misdirected and about notions other than the ones under discussion. We argue that the philosophically untutored are likely to have muddled intuitions and that professional philosophers are likely to have unmuddled intuitions. Although being umuddled does not, by itself, establish the reliability of the intuitions of professional philosophers, being muddled is enough to disqualify the intuitions of the philosophically untutored.

We then turn to the charge that, despite being unmuddled, professional philosophers still have biased intuitions. To evaluate this charge, we switch focus from the general notion of biased intuition to the more specific notion of theory-laden intuition. We argue that there is prima facie evidence - in the form of the presence of conflicts of intuition - for thinking that at least some of the intuitions of professional philosophers are theory-laden. In summary, we conclude that that there is no clean and easy answer to the question of whose intuitions should matter.
\end{abstract}

Keywords: Experimental philosophy; expertise; intuitions.

\section{Section I: Experimental philosophy and the appeal to expertise}

Experimental philosophy is a diverse movement mobilized around the idea that surveys that elicit the intuitions of the common folk about various philosophical topics are philosophically significant. "Experimentalists" put these surveys to work towards a variety of ends. Some claim that such surveys are the proper way to determine which philosophical theories have "intuitive plausibility" and which do not. ${ }^{2}$ Others argue that

\footnotetext{
${ }^{1}$ For more detailed descriptions of the unifying themes of (and the permutations within) experimental philosophy, see Alexander and Weinberg 2007, Knobe and Nichols 2008, and Alexander 2012.

${ }^{2}$ These experimentalists maintain that professional philosophers cannot determine what people's intuitions are about some topic from the armchair. Just because it seems intuitive to professional philosophers that $\mathrm{P}$ (where " $\mathrm{P}$ " is some proposition with
} 
certain problematic patterns revealed by the surveys - differences between which philosophical claims members of distinct cultures find intuitive, unstable intuitions (i.e. intuitions about some philosophical claim that flip-flop depending on the framing of the question), etc. - reveal that intuitions should carry no evidentiary value. Yet others use the intuitions elicited by such surveys as the basis for insights about cognitive processing. ${ }^{3}$ And there are more uses of the surveys beyond just these.

A common reaction leveled against such experimentalist projects, or at least against the first two projects described above, goes something like this (for expositional simplicity, we will use the topic of free will to frame the reaction):

\begin{abstract}
Who cares what a bunch of confused undergraduates think about free will? The only intuitions that matter are those of the trained philosophical mind, the professional philosopher. The fact that someone can run surveys on philosophically untutored minds and elicit results that contradict those of professional philosophers, or elicit results the reveal cultural differences or instability within a cultural group is neither here nor there when it comes to the role that intuitions should play in philosophical theorizing.
\end{abstract}

Let's call this response to the experimentalist project "the appeal to expertise". ${ }^{4}$ The basic idea is that the only intuitions that matter when evaluating the status of various philosophical theories are those of professional philosophers. If this were true, then the fact that the philosophically untutored have intuitions that differ from those of the professional philosopher would not undermine claims by professional philosophers concerning which theories are intuitive and which are not. Likewise, the fact that some philosophical content) is not sufficient evidence for asserting that $\mathrm{P}$ is intuitively plausible. Instead, we need to survey a variety of people in order to determine whether that $\mathrm{P}$ truly is intuitive plausible or not.

${ }^{3}$ Consider, for example, the discovery of "the Knobe Effect" - i.e. the tendency ordinary subjects have to attribute moral accountability and intent for a negative outcome when they are less likely to attribute them in structurally similar cases with positive outcomes. See Knobe 2003 for details.

${ }^{4}$ The appeal to expertise is found all over the place; see, for instance, Ludwig 2007 and Kauppinen 2007. 
of the philosophically untutored have intuitions that contradict the intuitions of another portion of the philosophically untutored, or the fact that the philosophically untutored have intuitions that exhibit instability, would not undermine the idea that the intuitions of professional philosophers have genuine evidentiary value.

The appeal to expertise threatens to cut many experimentalist projects off at the knees. Experimentalists have responded to this threat in a variety ways; in what follows, we focus upon two. First, some experimentalist argue that the claim that the professional philosopher's training gives her intuitions a superior epistemic status relative to those of the philosophically untutored is a nontrivial empirical claim. Weinberg et al. 2010 give this response to the appeal to expertise by marshaling empirical evidence to challenge the idea that the graduate training and professional experiences of philosophy $\mathrm{PhDs}$ increases the reliability of their intuitions. This empirical evidence includes: 1) studies that reveal that, in many domains, extensive training does not actually increase reliability of the judgments made about topics from within those domains $\left.{ }^{5}, 2\right)$ studies that show that expertise in a field does not automatically eliminate cultural biases, order effects, and other extraneous influences upon judgments made about topics from within that field ${ }^{6}$, and 3) studies that suggest that there is often little transfer of skills/abilities from the expert's (narrow) domain of specialization to other domains that seem intuitively

\footnotetext{
${ }^{5}$ In favor of this claim, Weinberg et al. cite, among others, the work of Camerer and Johnson 1991 and a meta-study by Shanteau 1992. The latter reveals that extensive training and experience in fields such as psychiatry, stock brokerage, and polygraph administration and reading do not to produce real expertise or increased reliability. ${ }^{6}$ Recently, Schwitzgebel and Cushman (2012) have demonstrated that this phenomenon extends to the case of philosophy. More specifically, they showed that the intuitions/judgments of professional philosophers on moral issues are susceptible to the kind of order effects that also influence the folk's intuitions/judgments on the same topics.
} 
similar. ${ }^{7}$ Weinberg et al. also raise a more general conceptual challenge to the appeal to expertise: namely, there is no obvious (non-question-begging) account of the feedback mechanism by which graduate students could hone their intuitions relative to "proper" intuitive judgments on any given philosophical topic.

To be clear, the empirical evidence is not completely one-sided on the question of the value of expertise in philosophy. For instance, Livengood et al. (2010) have found empirical evidence for thinking that professional philosophers are more reflective than both the philosophically untutored and people who have advanced degrees in areas other than philosophy. Camerer and Johnson (1991) provide empirical evidence for thinking that, in general, expertise in a field increases the ability to make subtle distinctions and to categorize stimuli in novel ways. The problem, of course, is that neither of these studies produces evidence that directly establishes the reliability of the intuitions of professional philosophers, which is the current point of contention.

In light of this last point, and in light of the aforementioned empirical evidence marshaled by Weinberg et al., the claim that the philosophical training and ongoing experiences of philosophy $\mathrm{PhDs}$ results in reliable philosophical intuitions is controversial and in need of argumentation and/or empirical support. As a result, the "armchairist" (the foil of the experimentalists) cannot simply assert that the training of the professional philosopher increases the reliability of her intuitions as though the truth of such a claim is obvious.

The second, more aggressive experimentalist response to the appeal to expertise involves the idea that earning a $\mathrm{PhD}$ in philosophy is actually detrimental to having

${ }^{7}$ For discussion and examples, see Feltovich et al. 2006 and Norman et al. 2006. 
superior intuitions. The idea is that the longer one studies philosophy the more biased one's intuitions become. ${ }^{8}$ According to this line of thought, the best subjects-i.e. the ones least likely to have biased intuitions - end up being the philosophically untutored. As a result, the undergraduate's intuitions should be accorded more evidentiary value than those of the professional philosopher.

In this paper, we attempt to make headway on both issues: the issue of whether professional philosophers have "superior" intuitions (given some sense of the word "superior") and the issue of whether their graduate training and ongoing experiences biases their intuitions. With regard to the first issue, our approach differs from most others in that we do not focus on the reliability (or lack thereof) of the intuitions of professional philosophers. Instead, we identify a significantly less controversial sense in which the intuitions of professional philosophers are preferrable to those of the philosophically untutored: professional philosophers are less likely to be "muddled" about various philosophical topics than are the philosophically untutored. ${ }^{9}$ Despite not having any direct implications for the question of whether the intuitions of professional philosophers are reliable or not, our discussion of muddled versus unmuddled intuition still has significant implications for the debates surrounding the appeal to expertise, for it reveals that at least some of the intuitions of the philosophical untutored should be disqualified on pains of those intuitions being muddled. This, in turn, raises a serious concern surrounding the philosophical significance of many experimentalist surveys.

\footnotetext{
${ }^{8}$ For examples of this experimentalist response to the appeal to expertise, see Machery et al 2004 and Knobe and Nichols 2008.

${ }^{9}$ In a way, our account will focus on something that is an extension of the ability tracked in Camerer and Johnson 1991.
} 
This may seem like a (relatively) clean victory for the armchairist, for she now possesses an argument in support of her claim that the intuitions of the professional philosopher are, in some sense, "superior" to those of the philosophically untutored. (More carefully, she has an argument for thinking that, unlike the philosophically untutored, professional philosophers will not be muddled in their intuiting. As we noted above, this is not the same thing as possessing an argument for thinking that the intuitions are professional philosophers are actually reliable.) But our account of what makes a professional philosopher likely to be unmuddled - i.e. her philosophical training —invites the charge that this same philosophical training ultimately biases the intuitions of professional philosophers.

In evaluating this charge, we shift gears from the general notion of "biased intuition" to the more specific notion of "theory-laden intuition". One way of evaluating the charge of theory-laden intuitions would be to develop (and defend) a theory of the psychological mechanism responsible for intuition and then examine whether philosophical training has deleterious or biasing effects upon the workings of that mechanism. In place of executing such a daunting project, we adopt a more modest strategy for approaching the question of theory-laden intuitions: We identify a plausible earmark for the presence of theory-laden intuitions - i.e. we identify a phenomenon that serves as prima facie evidence for the presence of intuitions that are theory-laden - and then show how this earmark/phenomenon is present in at least some cases of the intuitions of professional philosophers. In this way, we show that the experimentalist charge that the intuitions of professional philosophers are "biased" has at least some bite. 
As a result, neither side in this debate over who has "superior" intuitions is the straightforward winner.

\section{Section II: The philosophically untutored and muddled intuitions}

As we have seen, the claim that the training and ongoing experiences of professional philosophers makes their intuitions reliable is controversial. Rather than tackling this difficult issue, we want to focus on another sense in which the intuitions of the professional philosopher could be "superior" to those of the philosophically untutored. In his textbook on experimental philosophy, Joshua Alexander (2012, p. 9098) quickly identifies a number of candidate ways in which the intuitions of professional philosophers could be "superior" relative to those of the philosophically untutored: they could be more reliable, they could be framed using a superior theoretical language, they could stem from better concepts and theories, they could be better focused on the salient features of a scenario, etc. The sense in which professional philosophers could possess "superior" intuitions that we wish to focus upon falls under the idea that, as Alexander (2012, p. 93) puts it, philosophers have a "better understanding" of ordinary concepts than do the philosophically untutored. Our project in this section is to spell this idea out in more detail and see what implications it has for the appeal to expertise.

At the heart of our account is the notion of an intuition's being "muddled" or "unmuddled". It is important to note from the outset that the distinction between muddled and unmuddled intuitions is not the same as the distinction between unreliable and reliable intuitions; we will maintain that have unmuddled intuitions is a necessary, but not a sufficient, condition for having reliable intuitions. As will become clear later on, we think that the claim that professional philosophers are unlikely to be as muddled 
as the philosophically untutored is far less controversial, and far easier to establish, than any claim, pro or con, about the actual reliability of their intuitions.

Let's begin our discussion of "muddled" versus "unmuddled" intuitions by considering an activity central (in most cases) to professional philosophical practice: teaching. Imagine a professor preparing her opening lecture on the problem of free will. At some point during this lecture, she plans to elicit her class' intuitions on the question of whether moral responsibility is compatible with Determinism. With this aim in mind, what kind of lecture should she prepare? How should she go about eliciting this intuition? One way of doing so would be to write a typical definition of Determinism on the board and then simply ask her students whether, if Determinism were true, anyone would be morally responsible for their actions. Alternatively, she could ask her students whether specific persons in a Deterministic universe who commit specific crimes are morally responsible for their actions. ${ }^{10}$

If she ran her lecture in this manner, she would basically be doing what many experimentalists do with their surveys. To accomplish her mission as a teacher, however, she needs to do a lot more than simply prepare a bare-boned definition of Determinism and a question about its compatibility with moral responsibility. As a teacher, the challenge facing her is not just about eliciting an initial intuition from the students about this topic. It is also about making sure the student's intuitions about that topic are not muddled. For instance, are her students aware that Determinism isn't the same thing as Fatalism? (If not, then the intuition she elicits from them might be about whether Fatalism, not Determinism, is compatible with moral responsibility.) Are her

\footnotetext{
${ }^{10}$ For an interesting experimentalist discussion of the differences between asking the general question and the more specific question, see Nichols and Knobe 2007.
} 
students interpreting Determinism as entailing a kind of coercion or manipulation where the agent's conscious desires are bypassed? ${ }^{11}$ (If so, then the intuition she elicits may merely be the intuition that in a universe where one's conscious desires are bypassed, nobody is morally responsible for their actions.) Are they conflating Determinism with the general logical impossibility of having an entirely self-created self? ${ }^{12}$ (If so, then the intuition she elicits may about the general impossibility of being completely responsible for your own character, and not about the more specific threat that Determinism poses to moral responsibility.) Are they aware that we can still justify locking up dangerous individuals as a matter of social defense even if, strictly speaking, there is no moral responsibility? (If not, then the intuition she elicits may be about whether Determinism is compatible with a specific account of punishment, and not with moral responsibility in general.) Are they aware that if Determinism is true, then mental events, including acts of deliberation, are also determined? Are they perhaps implicitly assuming a nonreductive account of the mental that would make the mental exempt from physical determination? Are they aware of the difference between physical and mental constraints? Do they have an adequate idea of what it would be like to act both mentally and physically if all their actions were Determined? The list goes on and on...

In our combined years of teaching the Determinism/moral responsibility debate to beginning philosophy students, we have regularly had students fall victim to all of these conceptual confusions, blind spots, and more. This is not something for which they

\footnotetext{
${ }^{11}$ For examples of experimentalists who are sensitive to this particular way of being muddled about Determinism and moral responsibility, see Nahmias et al. 2006 and Nahmias and Murray 2010.

${ }^{12}$ For discussion of this particular threat to the idea of moral responsibility, see G. Strawson 1994.
} 
should be blamed; the notions of Determinism and moral responsibility are part of complicated nexus of interconnected concepts. For an undergraduate (or anyone else) not well versed in the logical geography of this complicated nexus, there is a danger that one's initial intuitions about the compatibility of Determinism and moral responsibility will be misdirected and instead be about other, related notions in the nexus or perhaps even be amalgams of several such intuitions. Getting a clear picture of this nexus-and thereby properly identifying and separating various intuitions regarding the relations between the concepts contained within it—typically requires a fair amount of intellectual labor and guidance. It typically requires a good textbook or a series of careful and detailed lectures from a trained philosopher. For most students, a cursory definition of Determinism and a reliance upon their unrefined understanding of "moral responsibility" is simply not enough of a map to allow them to make sure that the intuitions they have are properly directed at the issue at hand and not at other, possibly related, issues.

A teacher's task in "unmuddling" her students involves clearing up the misunderstandings, conflations, and vaguenesses in their understanding of the relevant concepts. Is it possible for her to provide this service without prejudicing her students one way or another? One way to press this question is to ask how our teacher decides which conceptual distinctions from the large nexus of interconnected concepts are the relevant ones to highlight for her students. After all, she may have strong opinions about this topic; she may, for instance, be a published incompatibilist who views many of the conceptual distinctions invoked by compatibilists as being irrelevant. Although some philosophy professors feel no compunction about teaching beginning students only what they take to be the correct answers to the debates under discussion, others understand 
their pedagogical mission more broadly. Those in the second camp act as though their job is to give their students as complete and as detailed a map of the conceptual terrain on this issue as possible, regardless of any intellectual commitments that might make parts of that terrain or particular concepts seem to them irrelevant or unhelpful. In short, these professors desire to give their students as clear of a view of the (current) conceptual terrain as possible without favoring one position over another. ${ }^{13}$ It is akin to trying to help the students to visually identify an object located across a dark room by turning up the lights and giving them glasses, but not by actually telling them what that object is.

As we've laid out the notion, being "unmuddled" about some philosophical topic does not, by itself, establish that your intuitions about that are reliable. Once students are unmuddled — once they have zeroed-in and properly identified and separated their intuitions regarding the relations between various notions contained within the nexus of concepts related to Determinism and moral responsibility—it doesn't follow that their intuitions are now likely to be true. Instead, all that follows is that their intuitions will at least be properly directed to the topic at hand-Determinism, not Fatalism; moral responsibility, not punishment more generally; etc. For this reason, we maintain that being unmuddled is a necessary, but not a sufficient, condition for having reliable intuitions; to have reliable intuitions about some topic, those intuitions must first be properly directed at the relevant concepts/ideas within the overall conceptual nexus, but there being so directed does not guarantee their reliability.

Our example has assumed that the teacher has a kind of "expertise" not shared with her beginning students; we've assumed that philosophy professors are less muddled

${ }^{13}$ This, of course, can be a difficult task in practice. 
than their students about the Determinism/moral responsibility debate. But what, exactly, makes them "experts" on this front? On what grounds can we justify the claim that they are less "muddled" - that they understand the relevant distinctions and, as a result, have intuitions that are more likely to be properly directed at the relevant topics- than beginning students on the Determinism/moral responsibility debate? The obvious answer links expertise on this particular front to training (and continuing experiences) as a professional philosopher. Professional philosophers have a competent grasp on the complex logical geography of interrelated concepts from this debate because they taken classes on these topics with experts, they have attended (and perhaps presented at) conferences on these topics, they have written dissertations, they have read (and perhaps even authored) articles, and books, and so on. ${ }^{14}$

Recall that we are not claiming that her undertaking of such activities makes her intuitions about these topics more reliable. As we saw earlier, that's a far more contentious (and difficult to establish) claim. Instead, we are making the weaker claim that the above requirements and activities of our professional philosopher make it the case that whatever intuitions she has about this topic are at least properly directed at the relevant ideas. All this weaker claim requires for its support is that professional philosophers have encountered the relevant conceptual distinctions repeatedly during their training and continuing experiences, and that they remember these distinctions.

\footnotetext{
${ }^{14}$ Recall that one of Weinberg et al's complaints was that there is no non-questionbegging account of a feedback mechanism that would allow graduate students to correct their intuitions and make them more reliable. There are, however, feedback mechanisms that would allow graduate students to discover which of their intuitions are muddled and to unmuddled them.
} 
Since, in asserting that the training of professional philosophers increases the likelihood of their being unmuddled, we are not claiming that their training also makes their intuitions reliable, we do not have to respond to the charge that, for all we know, philosophy is one of those domains where expertise does not increase reliability, or the charge that professional philosophers are still susceptible to order effects and cultural biases, or the charge that there is no (non-question-begging) feedback mechanism that allows graduate students in philosophy to hone the reliability of their intuitions. All we are claiming is that, in virtue of her training and ongoing professional activities, a professional philosopher will have repeatedly encountered (and subsequently remembered) the relevant distinctions in the complicated nexus of concepts involved in various philosophical debates. As a result, she will be far less likely to conflate, say, Determinism and Fatalism, or moral responsibility and social defense, etc. when thinking about whether Determinism is compatible with moral responsibility.

To be fair, there is one finding from empirical studies of expertise that could create trouble for our claim about the training and continuing experiences of professional philosophers resulting in unmuddled intuitions. The finding in question is that expertise tends to be extremely domain-specific: the set of skills developed in one's domain of expertise often do not transfer to other domains, even when the latter domains seem intuitively connected to the former. We are happy to concede this point and modify our claim in light of it. We will allow that professional philosophers can hold conceptual maps that are clear in places (the topics in which they are interested, write about, teach classes about, etc.) and dark and murky in others. A logician may not be in command of 
all the conceptual distinctions made by ethicists, a historian might be fuzzy on some of the concepts central to the philosophy of mathematics, and so on. ${ }^{15}$

With this qualification in mind, let's summarize the discussion so far. We think that the relatively weak claim that in the specific area/areas of philosophy in which a professional philosopher has trained, she possesses a clear view of the complicated nexus of interconnected concepts of that area/areas and, as a result, has unmuddled intuitions about those topics, is relatively uncontroversial. Despite being relatively uncontroversial, we think this claim has important (but largely unexplored) implications for the debate. For the claim that being unmuddled is a prerequisite for having reliable intuitions raises serious concerns about the experimentalist's core project and about the surveys at the heart of that project. For what's true in the classroom is also true in the lab and the field: if the experimentalist gives her subjects a definition of Determinism and then queries them about the compatibility of Determinism with moral responsibility, the resultant intuitions are likely to be muddled. In virtue of being so, these intuitions fail to meet a prerequisite for being reliable. This, in turn, casts serious doubt about the significance of the survey in question. To put the concern another way, if the experimentalist gives untutored subjects a definition of Determinism and then queries them about the compatibility of Determinism with moral responsibility, the resultant intuitions might be different from those of professional philosophers. This difference, however, might simply reflect a confusion on the part of the untutored about what they are being asked. At the very least, we should worry that we are not querying the same intuition from the

\footnotetext{
${ }^{15}$ As part of an ongoing project to understand the value of intuitions in philosophy, it would be interesting to gather empirical data determining whether and the degree to which professional philosophers are "less muddled" on philosophical topics outside their interests than graduate students, undergraduates, and the population more generally.
} 
untutored that we are from professional philosophers. We could be, in effect, comparing apples and oranges.

To their credit, experimentalists are not oblivious to the concern that their surveys could be eliciting intuitions that are misdirected or, as we prefer to put it, "muddled".

One potential remedy to this concern would be to provide some conceptual ground clearing prior to giving their surveys; in the case of the Determinism/moral responsibility question, for instance, experimentalists could explain the difference between Determinism and Fatalism, etc. prior to eliciting the intuition. ${ }^{16}$ This potential remedy runs a risk, however, for the additional framing may now become the source of instability in intuition rather than just revealing it. What's more, if the experimentalist is concerned that taking philosophy classes will cause one's intuitions to become biased, she better not give a miniature lecture on Determinism and moral responsibility prior to eliciting the intuition!

Another potential remedy for the experimentalist concerned about muddled intuitions is to try to frame the survey in such a way that subjects are less likely to be muddled. For example, in testing whether the philosophically untutored think Determinism is incompatible with moral responsibility, Nahmias et al. (2006) avoid using the word "Determinism" for fear that their subjects will conflate that notion with the notion of Fatalism. This is a step in the right direction, but it does not go far enough. As we saw earlier in our pedagogy-inspired example, conflating Determinism with Fatalism is just one of many ways that the philosophically untutored can be (and often are) muddled with respect to the Determinism/moral responsibility question. Recall just some

\footnotetext{
${ }^{16}$ For an attempt to flesh out this basic approach, see Kauppinen's (2007) discussion of "The Dialogue Model".
} 
of the issues that philosophy professors have to address in order to ensure that students really understand the question "Is Determinism compatible with moral responsibility?"Are students conflating Determinism with the general logical impossibility of having an entirely self-created character? Are they aware that we can still justify locking up dangerous individuals as a matter of social defense even if, strictly speaking, there is no moral responsibility? Are they aware that if Determinism is true, then mental events (including acts of deliberation) are also determined? Are they implicitly assuming a nonreductive account of the mental that would make the mental exempt from physical determination? Are they aware of the difference between physical and mental constraints? Do they have an adequate idea of what it would be like to act mentally and physically if all their actions were Determined? Etc. Simply avoiding the word "Determinism" in an effort to circumvent a possible conflation between Determinism and Fatalism does little to address the rest of these concerns.

So although we commend Nahmias et al. (2006) for being sensitive to some of the conceptual muddles that the philosophically untutored could fall into when thinking about Determinism — in particular, the conceptual muddles that arise from conflating Determinism with Fatalism — we think there are plenty of other ways that they could end up being muddled. As a further illustration of this concern, consider the following inhouse debate between experimentalists. Nahmias and Murray (2010) express concern over an experimentalist survey used by Nichols and Knobe (2007) where the latter avoid using the language of "free will" in their survey for fear of the layperson's misinterpreting this philosophical term of art. In contrast, Nahmias and Murray think it is acceptable to use this term in querying everyday subjects and instead raise doubt over 
Nichols and Knobe's substitute notion of a person's being "fully moral responsible", pointing out that the latter term could be easily misunderstood by the philosophical untutored in a number of ways.

This exchange between experimentalists working on Determinism and moral responsibility is a microcosm of the general concern we have about experimentalist studies that attempt to unmuddle their subjects by constructing their vignette in way to avoid these muddles. Is it really possible to write a vignette in a way that takes care of all the common ways of being muddled? In this particular debate between experimentalists, the concern is just about the use of the words "free will" and "fully morally responsible". As we saw earlier, however, there are a number of other, additional confusions that the philosophically untutored can, and will, fall victim to in considering experimentalists' vignettes about Determinism and moral responsibility. Here's a general way to frame our concern: Suppose you were going to teach a class to beginning students on whatever philosophical issue is the topic of an experimentalist's vignette. How much "unmuddling" would you anticipate having to do on that topic in order to get your students' intuitions property directed at the topic at hand? Do you think that an experimentalist could accomplish that same goal merely by constructing a short vignette that avoids the use of certain words like "free will" or "full moral responsibility"?

In effect, both of the experimentalist approaches described above attempt to unmuddle the subject before he answers the survey: the first does so by giving the subject a miniature lecture, the second does so by framing the vignette in way that helps the subject avoid various muddles. But there is another kind of approach that the experimentalist could take. Instead of actively trying to unmuddle her subjects, the 
experimentalist can instead attempt to retroactively separate subjects that are muddled from those that are not using control questions. For example, in a survey that queries subjects about knowledge, Weinberg et al. (2001) ask a control question that identifies subjects who are treating "knowledge" as being synonymous with "subjective certainty". In virtue of muddling these concepts, the reports of these particular subjects are retroactively disqualified.

A nice feature of this experimentalist response to the concern about muddled intuitions is that, if it is done correctly, it does not run the risk "contaminating" the intuitions of philosophically untutored subjects by philosophically educating them beforehand. Of course, a fairly large number of control questions may be required to separate the muddled from the unmuddled. Think, for instance, about all the ways a professor can anticipate beginning epistemology students being muddled about the concept of knowledge; conflating that concept with the concept of subjective certainty is one of these ways, but there are plenty of others as well. Our main concern about this approach, however, is that fails to address the central problem: namely, the possibility that most of the philosophically untutored subjects taking a survey are massively muddled on the topic of that survey. Suppose that someone gave a survey about knowledge that had enough control questions to catch all the ways that we might anticipate the philosophically untutored to be muddled about knowledge. Realistically, how many subjects will not have their surveys disqualified by their answers to this armada of control questions? Although this is an empirical question, we're not optimistic that, after running the gauntlet of control questions, there will be a sufficient number of remaining viable subjects. 
Let's pull together the key points gained from our discussion of muddled/unmuddled intuitions. First, the philosophically untutored may be (and often are) muddled about many philosophical questions. Second, in many extant experimentalist studies, too few steps have been taken to ensure that the intuitions that were elicited were unmuddled. Now that we've leveled these concerns against the experimentalist, we need to qualify them a bit. As we noted earlier, it's possible for professional philosophers to be muddled on certain topics. What's more, there could be some philosophical questions that do not presuppose a familiarity with a complicated nexus of inter-related concepts. In these cases, the risk of having muddled intuitions drops off considerably and, as a result, the professional philosopher and the philosophically untutored might both satisfy the prerequisite for having unmuddled intuitions. So we are not claiming that it is impossible to get unmuddled intuitions from the philosophical untutored. That said, we suspect that many of the experimentalist surveys that have been conducted query subjects about topics that would require those subjects to be familiar with a complicated network of concepts in order to give answers that are unmuddled. As a result, we suspect that many of the provocative experimentalist results currently being discussed in the literature involve (or could involve) muddled intuitions.

It's worthwhile to connect the central points made in this section to similar points that have already been made in the literature. The basic idea that being "unmuddled" gives the professional philosopher's intuitions a leg up on those of philosophically untutored is already floating around in the debate between the armchairist and the experimentalist. For instance, you find it in Sosa's 2007 article where he argues that 
undergraduates could have an ambiguous notion of moral responsibility that explains why they claim moral responsibility is compatible with Determinism in some surveys but not in others. You can also see it in Ludwig's 2007 piece when he states

\begin{abstract}
We should not expect antecedently that untrained subjects should be in an especially good position to give judgments in response to scenarios involving difficult questions about the semantics of proper names, for this is a domain of considerable complexity where our ordinary vocabulary is not especially precise. We should instead expect that the relevant experts in the field of philosophical semantics will be better placed to give answers which focus on the right features of the cases and what they are supposed to be responding to. (150)
\end{abstract}

There is even something close to our idea of unmuddled intuitions in Weinberg et al 2010 when they admit philosophers are "better at logic" than undergraduates. Typically, however, the idea of being "unmuddled" is discussed in a cursory manner, the emphasis instead being upon the question of whether the intuitions of the professional philosopher are reliable or not. We have bucked this trend by focusing solely, and in detail, upon the notion of unmuddled intuition. In doing so, we have not drawn any positive conclusions about the reliability of the intuitions of professional philosophers. Instead, we've focused on a negative conclusion: namely, that results of at least some experimentalist survey should be disqualified in virtue of the subjects of those surveys being muddled about the topic at hand.

For the record, our investigation into the notion of muddled/unmuddled intuitions has some implications for the armchairist as well. For instance, since being unmuddled is only a necessary condition for having reliable intuitions, an armchairist who acts as though her intuitions are reliable merely in virtue of their being unmuddled has not yet made her case. ${ }^{17}$ All she can really argue is that, in virtue of being unmuddled, she has

\footnotetext{
${ }^{17}$ To be clear, an armchairist might have a theory of epistemological under which intuitions are "justifiers" regardless of issues stemming from the reliability of the
} 
met an important prerequisite for having reliable intuitions, a necessary but not sufficient condition.

Although this last point is important, it isn't a fatal objection to the armchairist. To survive it, she has to find some other story about why the intuitions of professional philosophers are reliable, a story that doesn't merely cite the fact that they are unmuddled. In the next section, however, we will see that a case can be made for thinking that "being unmuddled" often comes with a substantial price: the price of having biased intuitions.

\section{Section III: Philosophical experts and "biased" (i.e. theory-laden) intuition}

With regard to having philosophical intuitions that are unmuddled, we've just articulated a general advantage that professional philosophers are likely to have over the philosophically untutored. In the case of intuitions about the compatibility of Determinism and moral responsibility, for instance, the professional philosopher who specializes on this topic is far more likely to have unmuddled intuitions - intuitions that are about the relevant issue and not a closely related but irrelevant one-in virtue of her command of the complex and inter-related nexus of concepts related to this topic than is someone who is philosophically untutored.

psychological mechanism that justifies them. For example, a Phenomenal Conservatist who maintains that seeming that $\mathrm{p}$ is prima facie justification for believing that $\mathrm{p}$ could argue that since intuitions involve certain propositions seeming to be true, that fact alone is sufficient for those intuitions being prima facie justifiers for various beliefs/theories. Since we are not offering a positive epistemological account of the status of intuitions in this paper, we will not take a stand on whether the justificatory status of intuitions is best understood from a Reliabilist perspective, the Phenomenal Conservatist perspective, or the perspective of any other epistemological theory. For additional discussion of these issues, see Goldman 2007. 
At this point, then, it appears that the armchairist has the upper hand over the experimentalist in the debate about whose intuitions should matter when doing philosophy. In response to the arguments from the previous section, however, experimentalists are likely to claim that the thing that makes the intuitions of professional philosophers unmuddled — their philosophical training and their continuing experiencescomes with a substantial cost: namely, biased intuitions. In this section, we investigate the merit of this charge. The conclusion we reach is that, on at least some topics, the complaint that professional philosophers have biased intuition has prima facie plausibility, even though the claim that all professional philosophers have intuitions that are biased on all topics is, at least currently, under supported.

Before arguing for this conclusion, we need to first fill out the notion of "biased intuition" in a bit more detail. We will interpret the claim that intuitions are "biased" as being analogous to the idea, advanced by some visual psychologists and philosophers, that perception is theory-laden. With regard to the latter, the basic idea is that theory that one holds about some object, event, etc. affects how that object, event, etc. looks when one experiences it. To borrow an example from Hanson (1961), the sunrise looks different to a "geocentric" astronomer than it does to a "heliocentric" astronomer: the former experiences the sun moving around a stationary Earth while the latter experiences a moving Earth whose horizon is revealing a stationary sun. The echo of this idea, in the case of intuition, would be that the theory that a professional philosophers holds about some domain — a theory that she acquires during her philosophical training-impacts her 
intuitions about claims made regarding that domain. ${ }^{18}$ My compatibilism, for instance, affects what claims about moral responsibility I find to be intuitively plausible and what claims about moral responsibility I do not find to be intuitively plausible. It might, for example, foreground one theory while ruling another out entirely. ${ }^{19}$

For the moment, let's suppose that the intuitions of professional philosophers are "biased" in the sense described above — let's suppose that they are theory-laden. Their being so would not automatically render them unreliable. As Paul Churchland (1979, 1988) has pointed out, when perception is laden with a correct theory, the result will be a more detailed, more accurate representation of the world than when perception is laden with a false theory. We see no reason why the same cannot be true of intuition that is laden with a true theory. So the problem with intuitions being theory-laden is not that those intuitions would be guaranteed to be unreliable. The problem, rather, is that they would be unable to serve as a theory-neutral foundation for philosophical theories. ${ }^{20}$ This is a problem for armchairists, for they are prone to act as though their intuitions are theory-neutral evidence for various philosophical theories. As experimentalists are fond of pointing out, armchairists often act as though any unmuddled mind would share their

18 This is not to claim that undergoing extensive philosophical training on some topic makes it inevitable that one will possess a theory about that topic. We mean to present this claim only as a rule of thumb: in general, undergoing philosophical training with regard to some topic is likely to result in your possessing a theory about that topic.

${ }^{19}$ This would be an instance of what Goldman (2007) calls the "theory of a concept"-in this case, it would be a theory about the content of the concept of moral responsibilityinfluencing my intuitions about various cases. This is in contrast to cases where concepts "embed" a theory - i.e. cases where a theory is already embedded within the content of a concept. In discussing the concern that intuitions are theory-laden, we are concerned about the former cases, not the latter.

${ }^{20}$ This is an echo of a point that Fodor (1990) makes against Churchland $(1979,1988)$. 
intuitions on topic $\mathrm{X}$ and, as a result, that their intuitions about $\mathrm{X}$ are theory-neutral evidence for their philosophical theory about $\mathrm{X}$.

Now that we've identified the threat that theory-laden intuitions provide to the armchairist's position, let's get to the $\$ 64$ question: are the intuitions of professional philosophers, in fact, theory-laden? The extant literature on this question is disappointing. Experimentalists often act as though the claim that the intuitions of professional philosophers are biased (which we are interpreting in terms of their being theory-laden) is obviously true and does not stand in need of defense. ${ }^{21}$ And, as we've seen in the previous section, armchairists often act as though it's obvious that the training that professional philosophers undergo do nothing but improve their intuitions.

Setting aside the various ways that graduate training might "improve" philosophical intuitions, let's focus on the specific question of whether it results in theory-laden intuitions. Experimentalists are likely to say yes, armchairists are likely to say no, and neither side provides much by way of argument for their answer. We will end up occupying a more modest position that maintains that at least some of the intuitions of professional philosophers are likely to be theory-laden and, as a result, cannot serve as theory-neutral evidence in favor of/against various philosophical theories.

What's the argument/evidence for this more modest conclusion? Let's start with a more general question: How might one go about arguing that professional philosophers have theory-laden intuitions? As guidance, let's consider some of the arguments have been offered for thinking that perceptual observation (not intuition) is theory-laden. Some have argued that perception relies upon inferences to move from impoverished

${ }^{21}$ See, for example, the presentation of the claim in Knobe and Nichols 2008 and in Machery at al 2004. 
retinal image to full percept and that these inferences make use of all the subject's standing beliefs, including her theoretical beliefs. Others have appealed to holistic theories of semantics, theories that entail that the content of an observational experience/belief is determined by its "position" within the overall network of a subject's beliefs. And others have offered concrete examples where one's theory about what one is looking at seems to change the way that thing looks.

With all this in mind, let's return to the question of whether intuitions are theoryladen. Since there is no consensus about the psychological mechanism by which intuitions are generated — or even over what an "intuition" is—an argument for thinking that intuitions are theory-laden that appeals to the psychological mechanism that generates intuitions and then claims that this mechanism is not informationally encapsulated relative to the greater corpus of the subject's beliefs is not likely to be very persuasive. In addition, semantic holism has fallen on hard times, so we'll also ignore a possible argument for thinking that intuitions are theory-laden that appeals to semantics. ${ }^{22}$ That leaves arguments for thinking that intuitions are theory-laden on the basis of concrete examples of intuitions that seem to be influenced by theory. This is the kind of argument that will be our focus in what follows.

In the case of observation, defenders of the theory-ladenness often point to ambiguous figures—e.g. the duck/rabbit—as concrete examples where theory seems to affect observation. ${ }^{23}$ In the case of intuitions, we submit that clashes of intuitions among

${ }^{22}$ For just some of the problems facing semantic holism in general, see Fodor and Lepore 1992.

${ }^{23}$ For an alternative account of ambiguous figures, an account that undermines the claim that ambiguous figures are evidence of the theory-ladenness of observation, see Fodor 1988 . 
professional philosophers can play a similar role-i.e. they are prima facie evidence for the existence of theory-laden intuitions. Our argument is as follows: there is an apparent tension between the fact that professional philosophers are unmuddled (in virtue of their training) and the fact that there is sometimes substantial disagreement between their intuitions. ${ }^{24}$ For if the training of professional philosophers ensures that their intuitions are properly directed at the relevant topic at question, then you would anticipate a convergence among their intuitions about that topic. But sometimes there is not a convergence of intuitions among professional philosophers. Given that one cannot explain these failures of convergence in virtue of the relevant intuitions being muddled, we submit that a plausible alternative explanation is that the failure of convergence is the result of the relevant intuitions being theory-laden. This, of course, is not the only conceivable explanation for a lack of convergence of intuitions among professionals about some topic. We do think, however, that it's a plausible explanation. For this reason, we will view disagreement among the intuitions of professional philosophers on various topics as being prima facie evidence for thinking that, at least with regard to those topics, their intuitions are theory-laden.

The armchairist may attempt to undermine this evidence in favor of the theoryladenness of the intuitions of professional philosophers by insisting that there are no major disagreements between the intuitions of professional philosophers. Indeed, some armchairists speak as though the entire philosophical community shares their intuitions about some topic; they speak as though widespread agreement between intuitions among professional philosophers is the norm. What's more, even though the conclusion of our

\footnotetext{
${ }^{24} \mathrm{We}$ want to thank an anonymous referee for suggesting this way of characterizing our argument.
} 
argument aids the experimentalist cause, the hard-nosed experimentalist may still want empirical evidence of the existence of disagreement among the intuitions of professional philosophers.

In light of these concerns, we'd like to spend some more time on the claim, central to our argument from this section, that there are clashes between the intuitions of professional philosophers. To start with, we want to emphasize that we are not saying that there are no instances of widespread agreement between the intuitions of professional philosophers. We are happy to concede, for example, that most professional philosophers will have the intuition that when a subject is in a Gettier-style scenario, she does not count as possessing knowledge despite possessing justified, true belief. But there are other cases, cases that are sometimes presented in this literature as though they involve widespread agreement among professional philosophers, where we think the real truth of the matter is far more complicated.

For example, consider a case that has been much-discussed in the experimentalist literature: Keith Lehrer's (1990) attempt to elicit intuitions in favor of Internalist accounts of knowledge via his “Truetemp” thought-experiment. Lehrer's case concerns a man, Truetemp, who has been surgically altered in such a way that he forms accurate beliefs about the current temperature; given a proper understanding of the surgery, the reader sees that Truetemp's beliefs about the temperature stem from a reliable process. Truetemp, however, is unaware of the source of his beliefs about the temperature and accepts them unreflectively. The relevant question is whether or not, when Truetemp comes to rightly believe that the current temperature is 104 degrees, he knows that it is. 
The intuition you are supposed to have, according to armchairist orthodoxy, is that he doesn't. In their discussion of this thought-experiment, Swain et al (2008, p. 140) claim "Generally, philosophers accept appeals to intuitions about the Truetemp Case as evidence against reliabilism." As we see it, however, this claim is a simplification of the actual situation. After all, a number of professional philosophers working in epistemology—and especially within the Reliabilist movement within epistemologyhave the intuition that animals can possess knowledge despite lacking internally accessible reasons in favor of their true beliefs. Surely some of these same philosophers will also have the intuition that Truetemp can possess the same type of "animal" knowledge. As a result, it is not really the case that professional philosophers are unified in having the intuition that Truetemp lacks knowledge. Part of what make this situation complicated, and misleading, is that some of the philosophers sympathetic to the claim that animals possess knowledge ultimately want to occupy a position that says that someone like Truetemp possesses one type of knowledge - the kind of knowledge possessed by animals — while lacking another type — the kind of knowledge that is unique to people. ${ }^{25}$ As a result, we suspect that when professional philosophers "agree" with Lehrer and admit to having the intuition that Truetemp lacks knowledge, the intuition that at least some of them have is really that that Truetemp lacks "knowledge" in one sense of the word. As we have just seen, however, this is compatible with also having the intuition that Truetemp has "knowledge" in another sense, a sense that is completely in step with Reliabilism. So what is described as being a case of widespread intuitive agreement among professional philosophers is, in fact, a case where there is actually

\footnotetext{
${ }^{25}$ Versions of this basic idea can be found in Bach 1985, Sosa 1997, and even in the recent work on an arch-Internalist, Bonjour (2007).
} 
multiple, importantly distinct intuitions - i.e. the intuition that Truetemp lacks knowledge tout court and the intuition that be lacks one kind of knowledge, but might well possess another type (of Reliabilist-friendly) knowledge.

To be fair, our discussion of the Truetemp case is largely speculation, from the armchair, about a single case where there appears to be agreement between the intuitions of professional philosophers. What concrete empirical evidence do we have for thinking that there are cases of clashing intuitions among professional philosophers? ${ }^{26}$ To start with, there is anecdotal evidence. We've all attended conferences where, at some point in the question and answer section of a talk, a speaker and her interlocutor end up at loggerheads with respect to their intuitions: one has an intuition that the other simply does not.

Do we have more than just anecdotal evidence? Unfortunately, we have not surveyed professional philosophers for their intuitions on various topics/thoughtexperiments. Nor are we aware of any such survey. That said, there are other surveys involving professional philosophers that we think provide indirect evidence for our claim that professional philosophers sometimes have clashes of intuitions. Consider, for instance, the survey conducted by David Chalmers and David Bourget, the results of which were posted on the PhilPapers website (http://philpapers.org/) in November 2009. This survey involved 30 questions on various philosophical topics and included among its subjects 1803 philosophy $\mathrm{PhD}$ or philosophy faculty members. We think, arguably, that a number of the questions on this survey can be viewed as eliciting the intuitions of subjects on well-known thought-experiments. For instance, there is a question of whether

\footnotetext{
${ }^{26} \mathrm{We}$ want to thank an anonymous referee for pressing this question.
} 
a teletransporter results in death or survival; there is a question of whether one ought to flip the switch or not in a trolley case where there are five people on the track ahead and one person on the side track; and there is a question about whether zombies are inconceivable, conceivable but metaphysically impossible, or metaphysically possible. (For our purposes, what matters about the last question is simply the distinction between those who think zombies are inconceivable and those who think they are conceivable.)

Of course, we can't know for sure whether the professional philosophers answering these questions were answering on the basis of their intuitive response to the described scenarios, on the basis of their theoretical commitments, or both. (We imagine, however, that any attempt to gather empirical evidence as to the intuitions of professional philosophers would be similarly stymied by the difficulty disentangling intuitions from theoretical commitments in professional philosophers.) That said, we think it's plausible that many answered on the basis of the intuitions they have about these scenarios. So what were the results? Do the "experts" converge with respect to how they answer? No. Among subjects who either possessed a $\mathrm{PhD}$ or were philosophy faculty members (a total of 1803 subjects), $34.7 \%$ thought the teletransporter resulted in survival, $31.4 \%$ thought it resulted in death, and $33.8 \%$ choose "other". In the trolley case, $66.1 \%$ thought you ought to flip the switch, $7.2 \%$ thought you ought not flip the switch, and $26.7 \%$ choose "other". And in the zombie case, 17.6\% thought zombies are inconceivable, 59.1\% thought that zombies are conceivable, and the other $23.8 \%$ choose "other". ${ }^{27}$ So even in the best case of "convergence" out of these three questions, the trolley case, only $66.1 \%$

\footnotetext{
${ }^{27}$ Recall that on this last question we are ignoring a difference between those who think that zombies are conceivable but not possible, and those who think that zombie are conceivable and possible
} 
of the subjects could be interpreted as having the same intuitions about the case in question.

Another source of indirect evidence for the existence of clashes of intuition among professional philosophers involves a recent experimentalist strategy of arguing that the intuitions of professional philosophers are influenced by features that are seemingly extraneous to the question at hand. For instance, Schultz et al. (2011) have acquired empirical evidence that suggests that the intuitions of professional philosophers about the free will/determinism is correlated with various personality traits, while Schwitzgebel and Cushman (2012) have acquired empirical evidence that suggests that the intuitions of professional philosophers are susceptible to order effects. If the intuitions of professional philosophers are, indeed, influenced by factors like these, then this is a reason to suspect that professional philosophers will not always agree with one another with regard to their intuitions. Those with one particular personality trait are likely to have one intuition about free will/determinism, while those with the opposing trait are likely to have a different intuition. Or those who are presented with a series of thought-experiments in one order are likely to have one intuition, while those presented with those thought-experiments in another order are likely to have another intuition.

Let's summarize the central argument of this section. We have identified a phenomenon - the disagreement among the intuitions of professional philosophers - that, when present, serves as prima facie evidence for the existence of theory-laden intuitions. The basic idea, recall, is that the possession of theory-laden intuitions is a plausible explanation of the apparent tension between the extensive training that professional 
philosophers receive - a training that allows them to have unmuddled intuitions - and the existence of conflict between the intuitions of those philosophers.

Although the professional philosophers do not have clashes of intuition on all topics, we adduced reasons for thinking that they do have clashes on intuition on at least some topics. So, pace the strong claim sometimes made by some experimentalists, we have not established that philosophical training inevitably leads to bias. If there are cases where professional philosophers agree with regard to the intuitively plausibility of some claim or position, then the prima facie evidence for theory-laden intuitions that we've been focusing upon-i.e. disagreement among the intuitions of professional philosophers - would be absent in those cases and, as a result, our case for theory-laden intuitions cannot be made.

In cases where there is disagreement between the intuitions of professional philosophers, however, there is prima facie evidence for the presence of theory-laden intuitions. This, in turn, speaks against the strong armchairist position that denies that the intuitions of professional philosophers are ever theory-laden. Given that we are willing to concede that some of the intuitions of professional philosophers may not be theoryladen, how large is our break from the armchairist position? For what it's worth, we suspect that disagreement in intuitions among professional philosophers is frequent, not exceptional, so we think that theory-laden intuitions are also frequent, not exceptional among the pros. But this is an empirical claim and until the relevant data is in — data detailing the exact extent of differences and similarities in intuition between experts on various philosophical topics — we will remain (officially) silent on the question of exactly how much of a break we are making from a armchairist position that maintains that 
intuitions are not theory-laden. The important point is that we now know at least one form of evidence to look for in exploring this issue.

\section{Section IV: Conclusion}

Experimentalists use the intuitions of the philosophically untutored, in a variety of ways, to cast doubt upon claims made about professional philosophers about whether or not some position is intuitively plausible. In response to this charge, the armchairist argues that only the philosophical intuitions of the experts (i.e. professional philosophers) should carry evidentiary value. The experimentalists, in turn, claims that the intuitions of professional philosophers are biased. The fundamental issue raised by this debate is the question of determining whose intuitions should matter and whose intuitions should be disqualified.

We have approached this issue by investigating an important prerequisite that intuitions must satisfy in order to count as reliable: they need to be unmuddled. Although it's possible for some undergraduates to be unmuddled on some philosophical topics, we've argued that many undergraduates are likely to be muddled on many philosophical topics. This, in turn, casts doubt upon many extant experimentalist studies, for we argued that not enough has been done in these studies to speak to the concern that the subjects might be muddled.

Although the intuitions of professional philosophers are not guaranteed to be unmuddled, it's far more likely that the intuitions of professional philosophers will meet this prerequisite for being reliable than those of the philosophically untutored. According to the experimentalist, however, the philosophical training that makes the intuitions of professional philosophers unmuddled also makes them biased. In evaluating this charge, 
we shifted the question of whether professional philosophers have intuitions that are biased to the question of whether they have intuitions that are theory-laden. We then made the case that disagreement between the intuitions of professional philosophers is prima facie evidence for thinking that those intuitions are theory-laden. Given that there is at least some such disagreement, there is prima facie evidence for thinking that at least some of the intuitions of professional philosophers are theory-laden.

In summary, neither party ends up being the clear winner. There is at least one sense in which the intuitions of the professional philosopher are likely to be "superior" to those of the philosophically untutored: the intuitions of the former are less likely to be muddled than the intuitions of the latter. This is a victory (of sorts) for the armchairist. But there is also evidence for thinking that at least some of the intuitions of those professional philosophers are theory-laden, which is a victory (of sorts) for the experimentalist. At the end of the day, then, there is no simple answer to the question of who has the superior intuitions. Unmuddled undergraduates, if they can found, would be good candidates. We have suggested, however, that for most philosophical topics such undergraduates are unlikely to be found. Professional philosophers whose intuitions are not theory-laden would be good candidates, if there were such philosophers. Given the preliminary test we developed for the presence of theory-laden intuitions, however, there is evidence that at least some of the intuitions of professional philosophers, on some topics, are theory-laden. And in absence of a well-worked out account of the psychological mechanism that generates intuitions, it remains unclear how widespread the phenomena of biased intuitions are among the professionals. As a result, the idea that intuitions serve as theory-neutral foundations for philosophical theories - and the idea 
that the intuitions of certain groups (e.g. the philosophically untutored, the philosophical experts, etc.) are poised to play this role-remains very much in doubt.

\section{Works cited}

Alexander, J. (2012) Experimental Philosophy: An Introduction. Polity: Malden, MA.

Alexander, J. and Weinberg, J (2007) “Analytic Epistemology and Experimental Philosophy”, Philosophy Compass 2(1): 56-80.

Bach, K. (1985) “A Rationale for Reliabilism”, The Monist 68: 246-263.

Bonjour, L. and Sosa, E. (2003) Epistemic Justification: Internalism vs. Externalism and Foundations vs. Virtues. Blackwell Publishing: Malden, MA.

Camerer, C.F. and Johnson, E.J. (1991) The process-performance paradox in expert judgment: How can experts know so much and predict so badly? In K. A. Ericsson \& J. Smith (Eds.), Toward a general theory of expertise: Prospects and limits. Cambridge University Press: Cambridge, 195-217.

Churchland, P. (1979) Scientific Realism and the Plasticity of the Mind. Cambridge University Press: Cambridge.

Churchland, P. (1988) "Perceptual Plasticity and Theoretical Neutrality", Philosophy of Science 55 (2): 167-187.

Feltovich, P. J., Prietula, M. J., and Ericsson, K. A. (2006) "Studies in expertise from psychological perspectives", in K. A. Ericsson, N. Charness, P. J. Feltovich, and R. R. Hoffman (eds.), The Cambridge Handbook of Expertise and Expert Performance. Cambridge University Press: Cambridge, 41-68.

Fodor, J. (1990) “Appendix: A Reply to Churchland's 'Perceptual Plasticity and Theoretical Neutrality", in J. Fodor, A Theory of Content and Other Essays. The MIT Press: Cambridge, MA, 253-263.

Fodor, J. and Lepore, E. (1992) Holism: A Shopper's Guide. Blackwell Publishers: Cambridge.

Goldman, A. (2007) "Philosophical Intuitions: Their Target, their Source, and their Epistemic Status", Grazer Philosophische Studien 74: 1-26.

Hanson, N. (1961) Patterns of Discovery. Cambridge University Press: Cambridge.

Kauppinen, A. (2007) “The Rise and Fall of Experimental Philosophy”, Philosophical Explorations 10 (2): 95-118. 
Knobe, J. (2003) "Intentional action and side effects in ordinary language", Analysis 63 (3): 190-194.

Knobe, J. and Nichols, S. (2008) “An Experimental Philosophy Manifesto", in J. Knobe and S. Nichols (eds.), Experimental Philosophy. Oxford University Press: Oxford, 3-14.

Lehrer, K. (1990) Theory of Knowledge. Westview Press: Boulder, CO.

Livengood, J., Sytsma, J., Feltz, A., Scheines, R., and Machery, E. (2010) "Philosophical Temperament", Philosophical Psychology 23: 313-330.

Ludwig, K. (2007) "The Epistemology of Thought Experiments: First Person versus Third Person Approaches", Midwest Studies in Philosophy 31: 128-159.

Machery, D., Mallon, R., Nichols, S., and Stich, S. (2004) "Semantics, Cross-Cultural Style", Cognition 92: B1-B12.

Nahmias, E., Morris, S., Nadelhoffer, T., and Turner, J. (2006) "Is Incompatibilism Intuitive?", Philosophy and Phenomenological Research 73 (1): 28-53.

Nahmias, E. and Murray, D. (2010) "Experimental Philosophy of Free Will: An Error Theory for Incompatibilist Intuitions", in J. Aguilar, A. Buckareff and K. Frankish (eds.), New Waves in Philosophy of Action. Palgrave-Macmillan: New York, 189-216.

Nichols, S. and Knobe, J. (2007) "Moral Responsibility and Determinism: The Cognitive Science of Folk Intuitions", Nous 41: 663-685.

Norman, G., Eva, K., Brooks, L., and Hamstra, S. (2006) "Expertise in medicine and surgery", in A. Ericsson, N. Charness, P. J. Feltovich, and R. R. Hoffman (eds.), The Cambridge handbook of expertise and expert performance. Cambridge University Press: Cambridge, 339-353.

Schwitzgebel, E. and Cushman, F. (2012) "Expertise in Moral Reasoning? Order Effects on Moral Judgment in Professional Philosophers and Non-Philosophers", Mind and Language 27 (2): 135-153.

Schulz, E., Cokely, E. T. and Feltz, A. (2011) "Persistent Bias in Expert Judgments about Free Will and Moral Responsibility: A Test of the Expertise Defense", Consciousness and Cognition 20: 1722-31.

Shanteau, J. (1992) "Competence in experts: The role of task characteristics", Organizational Behavior and Human Decision Processes 53: 252-266.

Sosa, E. (1997) "Reflective Knowledge in the Best Circles", Journal of Philosophy 94 (8): 410-430. 
Sosa, E. (2007) “Experimental Philosophy and Philosophical Intuition”, Philosophical Studies 132: 99-107.

Strawson, G. (1994) “The Impossibility of Moral Responsibility", Philosophical Studies 75: 5-24.

Swain, S., Alexander, J., and Weinberg, J. (2008) "The Instability of Intuitions: Running Hot and Cold on Truetemp", Philosophy and Phenomenological Research 76 (1): $138-155$.

Weinberg, J., Nichols, S., and Stich, S. (2001) "Normativity and Epistemic Intuitions", Philosophical Topics 29: 429-490.

Weinberg, J., Gonnerman, C., Buckner, C. and Alexander, J. (2010) “Are Philosophers Expert Intuiters?”, Philosophical Psychology 23(3): 331-355. 